Proceedings

\title{
Outcomes Assessment of Sustainable and Innovatively Simple Lifestyle Modification at the Workplace-Drinking Electrolyzed-Reduced Water (OASIS-ERW): A Randomized, Double-Blind, Placebo-Controlled Trial ${ }^{\dagger}$
}

\author{
Young Ah Choi 1,*, , Dong Hyeon Lee $2, \neq$, Doo-Yeoun Cho ${ }^{3}$ and Yong-Jae Lee ${ }^{4}$ \\ 1 Department of Family Medicine, Bundang Jesaeng General Hospital, Seongnam-si 13590, Gyeonggi-do, \\ Korea \\ 2 Department of Physiology, School of Medicine, CHA University, Seongnam-si 13488, Gyeonggi-do, Korea; \\ leedh@cha.ac.kr \\ 3 Department of Clinical Pharmacology, School of Medicine, CHA University, Seongnam-si 13496, \\ Gyeonggi-do, Korea; dooycho@cha.ac.kr \\ 4 Department of Family Medicine, Yonsei University College of Medicine, Seoul 06273, Korea; \\ ukyjhome@yuhs.ac \\ * Correspondence: oasistrial@naver.com; Tel.: +82-31-779-0155 \\ + Presented at the 1st International e-Conference on Antioxidants in Health and Disease, 1-15 December \\ 2020; Available online: https://cahd2020.sciforum.net/. \\ $\ddagger$ Both authors contributed equally to this study.
}

Published: 30 November 2020

\begin{abstract}
Oxidative stress has been implicated in many diseases as well as aging. Electrolysis of water produces electrolyzed-reduced water (ERW) rich in hydrogen molecules and hydrogen atoms (active hydrogen) near the cathode, both of which have been shown to contribute to reduced oxidative stress and improve antioxidant potential by scavenging reactive oxygen species (ROS). We investigated the effects of drinking ERW on biomarkers of oxidative stress and health-related indices in healthy adults at the workplace. This study was a randomized, double-blind, placebocontrolled clinical trial. Sixty-five participants were allocated into two groups. Of these, 61 received intervention (32 ERW and $29 \mathrm{MW}$ [mineral water]), and were instructed to drink $1.5 \mathrm{~L} /$ day of ERW or MW for eight weeks. Biomarkers of oxidative stress and health-related indices were assessed at baseline, four, and eight weeks. Fifty-three subjects completed the study. Of the primary outcome variables assessed, a significant interaction between the group and time was shown in the diacronreactive oxygen metabolites (d-ROMs) and biological antioxidant potential, with d-ROMs levels in the ERW group significantly decreased at eight weeks compared with those in the MW group. Among the secondary outcome variables, total, visceral, and subcutaneous fat mass showed a significant change at different time points, with a significant interaction observed between the group and time. Drinking ERW daily could be suggested as effective, sustainable, and innovatively simple lifestyle modification in healthy adults to reduce oxidative stress, increase antioxidant potential, and decrease fat mass.
\end{abstract}


The 1st International Electronic Conference on Antioxidants in Health and Disease, 1-15 December 2020

Keywords: oxidative stress; electrolyzed-reduced water; biomarkers of oxidative stress; reactive oxygen metabolites; biological antioxidant potential; fat mass; lifestyle modification

\section{Introduction}

Free radicals were first described in 1950 [1] and refer to highly unstable and reactive atoms or molecules, owing to unpaired electrons found in their outer orbit [2]. Reactive oxygen species (ROS) including reactive nonradical derivatives of oxygen and oxygen-centered radicals [2], are produced not only by natural biological processes but are also generated in response to external stimuli, such as ultraviolet (UV) radiation, infections, heavy metals, drugs, strenuous exercise [3,4]. Oxidative stress [5] has been shown to result in oxidative damage to various macromolecules [2,5-8], and have been implicated as an etiological agent in many pathological processes including aging $[2,6,9,10]$, radiation injury, cardiovascular disease, neurological diseases, and cancers [3]. Diverse strategies exist for estimating oxidative stress status, including the detection of free radicals, ROS, damaged macromolecules from oxidative stress, antioxidant capacity, and antioxidant enzymes as well as health-related indices for altered medical conditions resulting from oxidative stress [7,11].

Electrolyzed-reduced water (ERW) produced near the cathode during water electrolysis [12]is rich in hydrogen atoms and hydrogen molecules, low in dissolved oxygen, with an alkaline $\mathrm{pH}$, and has negative oxidation-reduction potential (ORP) $[13,14]$. An increasing number of studies have been conducted on alkaline and ERW since the effectiveness of ERW at scavenging ROS in vitro as well as its ability to protect against oxidative stress-induced DNA damage [15] was demonstrated.

ERW has been shown to suppress oxidative stress by improving the function of antioxidant enzymes in U937 cell line [16], protect neural cells from oxidative damage [17], inhibit tumor angiogenesis [18], enhance apoptosis of leukemia cells (HL-60) [12,19], shorten cancer cell telomeres $[14,20]$, and suppress invasion of human fibrosarcoma HT-1080 cells [21]. There was also a noteworthy study after the Fukushima disaster in 2011, suggesting that radionuclides, such as cesium and iodine, could be removed by an ERW-producing apparatus [22]. In animal studies, ERW was effective in lowering the levels of blood glucose in both type 1 and type 2 diabetic mice models [23], lowering plasma triglycerides levels and suppressing lipid peroxidation levels [24], reducing lipopolysaccharide (LPS)-induced neuroinflammation [25], demonstrating neuroprotection in cisplatin-induced kidney damage and improving oxidative stress biomarker levels [26], as well as prolonging the lifespan of nematodes [27] and mice [28]. Similarly, ERW was reported to reduce oxidative stress [29] and erythrocyte impairment [30] while improving T-cell damage [31] in patients with end-stage renal disease undergoing hemodialysis.

Meanwhile, natural reduced water has been reported to inhibit alloxan-induced $\beta$-cell apoptosis [32], lower glucose levels in alloxan-induced mice [32], suppress anxiety in rats [33], and increase the activity of natural killer cells in healthy volunteers [34]. Moreover, drinking alkaline MW was shown to lower the bone resorption marker in adults with sufficient calcium [35] and to significantly decrease the concentration of lactic acid at rest in athletes in a clinical trial [36]. In an open-label pilot study, consumption of hydrogen-rich water supplemented with a mineral stick improved indices related to oxidative stress and metabolic syndrome [37].

Health promotion programs adopting lifestyle modifications at the workplace are being implemented in several countries [38]. Several randomized clinical trials have been conducted to assess the effects of these healthy behaviors at the workplace, some of which reported meeting their primary endpoint, while others did not [39-42]. Nevertheless, these trials have raised questions regarding issues related to sustainability, affordability, and cost-effectiveness in terms of public and planetary health $[38,43]$.

The objective of this study was to assess the effects of sustainable and innovatively simple lifestyle modification at the workplace, namely drinking ERW for eight weeks, on biomarkers of oxidative stress and health-related indices in healthy adults. 
The 1st International Electronic Conference on Antioxidants in Health and Disease, 1-15 December 2020

\section{Materials and Methods}

\subsection{Overview of the Study Design}

We conducted a single-center, double-blind, placebo-controlled, parallel-group study in South Korea, in accordance with the "Ethical principles for medical research involving human subjects" defined in the declaration of Helsinki in 1975 (last updated in 2018), and following the Consolidated Standards of Reporting Trials (CONSORT) guidelines. The institutional review board of Bundang Jesaeng Hospital in Korea approved the study (IRB DMC 2018-11-009), and all subjects provided informed consent prior to participation.

\subsection{Participants and Eligibility Criteria}

The inclusion criteria for our study were: (1) subjects who voluntarily agreed to participate and signed informed consent, and (2) healthy volunteers between the ages of 18 and 65 years old (including patients with controlled hypertension or diabetes mellitus).

\subsection{Study Setting and Interventions}

This study was conducted at Bundang Jesaeng Hospital in Seongnam, South Korea, from February 2019 to May 2019. Five ERW-producing apparatus sets (AML 3010S, Alkamedi Co. Ltd., Anyang, Korea) were installed at five different locations throughout the hospital (OASIS-O area, OASIS-A area, OASIS-S1 area, OASIS-S2 area, and OASIS-I area). Each installed device consisted of two units. The first was a carbon filter unit that purified tap water for the production of MW, whereas the second was an electrolysis unit consisting of five platinum (Pt)-coated titanium (Ti) electrode plates separated by semipermeable membranes for producing ERW [17,22]. Purified MW flows into the electrolysis unit, where it becomes electrolyzed while passing through the gap between the $\mathrm{Pt}-\mathrm{Ti}$ electrodes [22]. ERW containing hydrogen $\left(\mathrm{H}_{2}\right)$ gas and hydroxide ions $\left(\mathrm{OH}^{-}\right)$are produced at the cathode [12], whereas electrolyzed oxidized water containing oxygen $\left(\mathrm{O}_{2}\right)$ gas and hydrogen ions $\left(\mathrm{H}^{+}\right)$ are produced at the anode [12] by electrolysis of water. ERW produced by electrolysis devices generally exhibits high $\mathrm{pH}$, low ORP, and high dissolved hydrogen [12,13,22].

Sixty-five participants were allocated into two groups; of these, 61 received intervention (32 for ERW and 29 for MW), and participants were instructed to drink $1.5 \mathrm{~L} /$ day of water from the devices allocated to their group for eight weeks.

\subsection{Outcome Variables}

The primary outcome of our study was to evaluate oxidative stress biomarkers including measurement of serum biological antioxidant potential (BAP), diacron-reactive oxygen metabolites (d-ROMs), oxidized low-density lipoprotein (oxLDL), superoxide dismutase (SOD), and catalase (CAT) levels; urine malondialdehyde (MDA) and 8-hydroxydeoxyguanosine (8-OHdG) levels; and plasma glutathione peroxidase (GPx) levels. OxLDL, a parameter of protein oxidation, was added after the study commenced to estimate the oxidative stress in more diverse aspects. The secondary outcome was to evaluate health-related indices, including the biochemistry profile (aspartate aminotransferase (AST), alanine aminotransferase (ALT), low-density lipoprotein (LDL) cholesterol, triglyceride, glucose, insulin, homeostatic model assessment for insulin resistance (HOMA-IR), cortisol, total bilirubin, gamma-glutamyltransferase (GGT), uric acid, lactic acid, alkaline phosphatase (ALP), serum calcium, urine calcium), natural killer (NK) cell activity, advanced glycation end product (AGE) of skin, fat mass (total, visceral, and subcutaneous), cardio-ankle vascular index (CAVI), heart rate variability (HRV), whole-body phase angle (PhA), as well as the implementation of questionnaires to assess stress (Brief Encounter Psychosocial Instrument-Korean version (BEPSI-K)), fatigue (Brief Fatigue Inventory (BFI) and Fatigue Severity Scale (FSS)), and Health-Related Quality of Life (HRQoL) (36-Item Short Form Survey (SF-36)). Primary and secondary outcome variables were assessed at baseline as well as after 4 weeks and 8 weeks of intervention. 
The 1st International Electronic Conference on Antioxidants in Health and Disease, 1-15 December 2020

2.5. Sample Size

The sample size was determined using the G Power 3.1 program [44].Cohen's convention for effect size (Cohen 1977) considering the potential dropout rate of $35 \%$ [45,46].

\subsection{Randomization, Allocation, and Blinding}

Randomization was conducted by an independent investigator not otherwise involved in the clinical trial using the $\mathrm{R}$ package 3.5.2. (2018, The R Foundation for Statistical Computing) [47]. Accordingly, a 1:1 allocation to the green or blue group was accomplished using permuted block randomization. The $\mathrm{pH}$ of the water in each electrolysis apparatus (ten apparatuses, five for ERW group, and five for MW group) was defined outside the hospital, before installation, and was blinded to investigators, participants, and the research manager. Meanwhile, a photo of each bottle (blue or green) pertaining to ERW or MW was attached on the surface of each apparatus by the engineer of the company who installed the apparatus. The participants assigned to the two groups (blue or green) were instructed to drink water from the apparatus on which the photo of the bottle of the same color with their group name was attached.

\subsection{Measurement of Outcome Variables}

The d-ROMs and BAP test were performed according to the manufacturer's instructions (Wismerll, Tokyo, Japan). The d-ROMs test evaluates the status of oxidative stress by determining hydroperoxides $(\mathrm{ROOH})$ levels [48] and of diverse organic compounds (lipids, proteins, nucleic acids, etc.) levels [49,50]. The standard reference level for d-ROMs was 250-300 U.CARR [51,52]. The BAP test provides a global measurement of many antioxidants [53,54], based on the ability of a blood sample to reduce ferric ions to ferrous ions [53-55]. Urine MDA was measured using an enzymelinked immunosorbent assay (ELISA) and the OxiSelect ${ }^{\text {TM }}$ TBARS assay kit (Cell Biolabs, San Diego, CA, USA) according to the manufacturer's instructions[56]. Urine 8-OHdG was assessed by competitive ELISA using the "8-OHdG check" kit (JaICA, Fukuroi,Japan) based on a monoclonal antibody specific for quantification of $8-\mathrm{OHdG}[57,58]$. Oxidized low-density lipoprotein (oxLDL) was determined using the Mercodia oxLDL ELISA kit (Mercodia, Uppsala, Sweden) [58]. All enzymatic activities were evaluated using assay kits (Cayman Chemicals, Ann Arbor, MI, USA) following the manufacturer's instructions [59,60]. The absorbance of MDA, 8-OHdG, oxLDL, and GPx were measured colorimetrically, using an ELISA microplate reader (VersaMax, Molecular Devices, San Jose, CA, USA) [56-60].

The CBC was measured with an Advia 2120 (Siemens Healthcare Diagnostics, Erlangen, Germany), while the neutrophil to lymphocyte ratio (NLR) was calculated by dividing the absolute neutrophil count by the absolute lymphocyte count [61]. The levels of HbA1c were measured using an HLC-723 ${ }^{\circledR}$ G11 glycohemoglobin (HbA1c) automated analyzer (Tosho Co., Ltd., Tokyo, Japan) [62]. The activity of natural killer cells was measured using the NK Vue ${ }^{\mathrm{TM}}$ kit (ATgen, Sungnam, Korea) according to the manufacturer's instructions[63].

The AGEs were determined using an AGE Reader (DiagnOptics, Groningen, Netherlands), as previously described [64], and skin autofluorescence was expressed in arbitrary units (AU) [65,66]. The CAVI, used for assessment of arterial stiffness [67], was measured using the VASERA VS-1000 automatic pulse wave analyzer (Fukuda Denshi Co. Ltd., Tokyo, Japan) as previously described $[62,68]$. The arterial pressure waveforms of the brachial and ankle arteries, phonocardiography, and electrography were measured, and CAVI was automatically calculated by the analyzer [69-71]. Parameters of HRV, including the time and frequency domains monitoring the balance and activity of the autonomic nervous system, were analyzed using the SA-6000 heart rate variability analysis system (Medicore Co.,Ltd., Seoul, Korea) according to the manufacturer's instructions [72,73]. PhA was measured using the InBody S10 multifrequency bioelectrical impedance analyzer (InBody, Seoul, Korea) [74], and total $\mathrm{PhA}$ was calculated from reactance $(X c)$ and impedance $(Z)$ [75]. The BEPSI-K [76,77], BFI [78] and FSS [79], and SF-36 questionnaire [80] were measured by questionnaries. 
The 1st International Electronic Conference on Antioxidants in Health and Disease, 1-15 December 2020

\subsection{Data Analysis}

Data were analyzed using the IBM SPSS Statistics for Windows Software (Version 22.0, Armonk, NY, USA). The values presented in the text were expressed as means (M) \pm standard deviation (SD). When comparing the continuous variables between the ERW and MW groups at baseline, the Student's t-test or the Mann-Whitney $U$ test was used. For categorical response variables, the differences between the two groups were assessed using the Pearson's chi-squared test, Fisher's exact test, or linear-by-linear association. To determine differences between groups over time, analysis of variance with repeated measures with the post hoc Bonferroni adjustment for multiple comparisons was performed. Results were considered to be significant at $p<0.05$.

\section{Results}

Initially, 81 subjects approached for screening. Of these, 65 subjects were enrolled in the study and randomly assigned into the ERW $(n=32)$ or MW group $(n=33)$. A total of 61 subjects received the allocated intervention and underwent a 4-week follow-up evaluation. After the scheduled followup, 29 in the ERW and 24 in the MW group, completed the study and were assessed for primary and secondary outcomes (per-protocol (PP) analysis) (Figure 1).

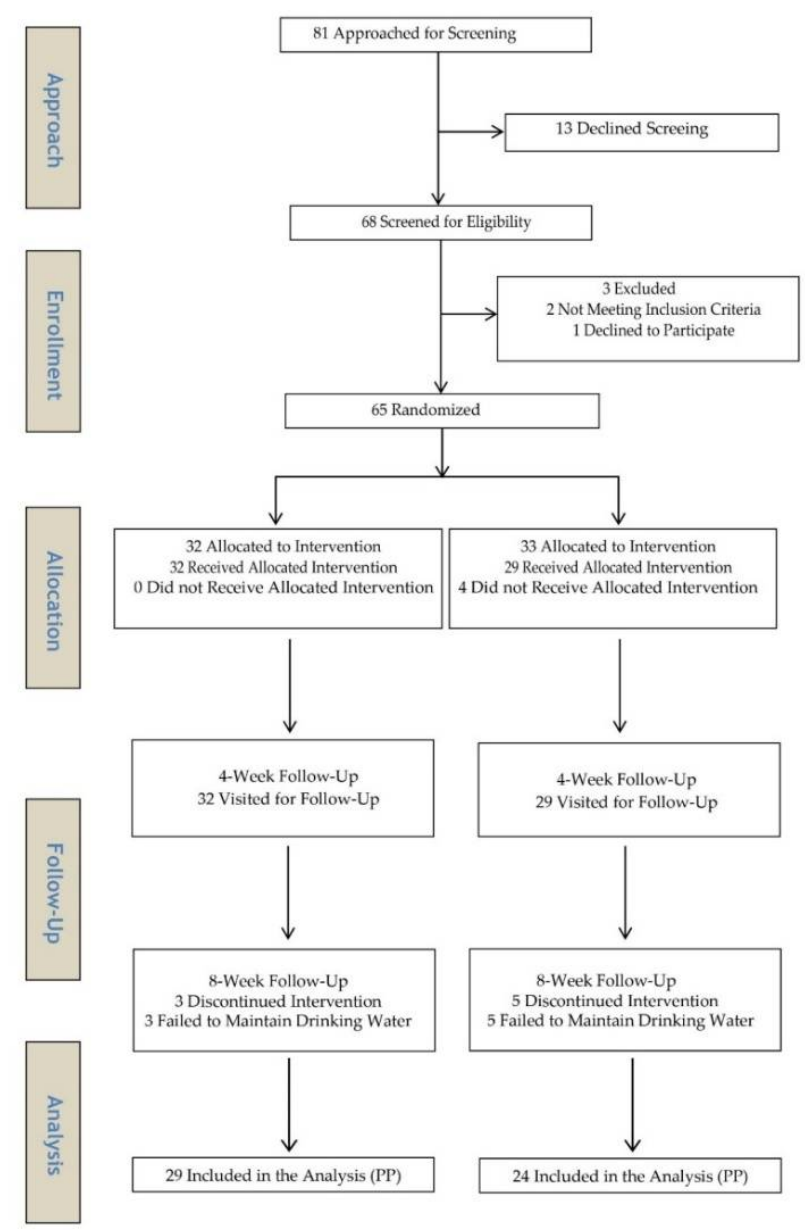

Figure 1. A Consolidated Standards of Reporting Trials (CONSORT) flow diagram. 
The 1st International Electronic Conference on Antioxidants in Health and Disease, 1-15 December 2020

3.1. Baseline Characteristics of Study Participants

The Baseline demographic and clinical characteristics of the study participants are presented in Table 1. No significant differences were observed between the two groups, except for d-ROMs, the $p$ value of which was only slightly below $0.05(p=0.046)$ (Table 1$)$.

55Table 1. Baseline characteristics of study participants.

\begin{tabular}{|c|c|c|c|c|}
\hline Characteristic & & $\begin{array}{c}\text { ERW } \\
(n=29)\end{array}$ & $\begin{array}{c}\text { MW } \\
(n=24)\end{array}$ & $p$-Value \\
\hline Demographic & years & & & \\
\hline Age & & $39.3 \pm 8.9$ & $41.0 \pm 9.3$ & $0.523_{-}^{*}$ \\
\hline Sex & no. $(\%)$ & & & $1.000 \pm$ \\
\hline Female & & $25(86.2 \%)$ & $21(87.5 \%)$ & \\
\hline Male & & $4(13.8 \%)$ & $3(12.5 \%)$ & \\
\hline Marital status & no. (\%) & & & $0.378 \ddagger$ \\
\hline Married & & $18(62.1 \%)$ & $12(50.0 \%)$ & \\
\hline Single & & $11(37.9 \%)$ & $12(50.0 \%)$ & \\
\hline Educational level & no. (\%) & & & $0.701 \S$ \\
\hline High school & & $3(10.3 \%)$ & $2(8.3 \%)$ & \\
\hline College/University & & $21(72.4 \%)$ & $17(70.8 \%)$ & \\
\hline Postgraduate & & $5(17.2 \%)$ & $5(20.8 \%)$ & \\
\hline Occupation & no. (\%) & & & $0.886 \S$ \\
\hline Professionals & & $6(20.7 \%)$ & $5(20.8 \%)$ & \\
\hline White collar & & $20(69.0 \%)$ & $17(70.8 \%)$ & \\
\hline Blue collar & & $3(10.3 \%)$ & $2(8.3 \%)$ & \\
\hline \multicolumn{5}{|l|}{ Clinical } \\
\hline d-ROMs & U.CARR & $301.3 \pm 68.6$ & $347.3 \pm 94.9$ & $0.046^{*}$ \\
\hline BAP & umol/L & $2027.4 \pm 226.9$ & $2015.7 \pm 274.8$ & $0.734 \|$ \\
\hline TBARS (MDA) & $\mu \mathrm{M}$ & $9.88 \pm 4.67$ & $8.90 \pm 5.98$ & $0.506_{-}^{*}$ \\
\hline 8-OHdG & $\mathrm{ng} / \mathrm{mL}$ & $14.33 \pm 6.88$ & $10.90 \pm 6.42$ & $0.069_{-}^{*}$ \\
\hline oxLDL & $\mathrm{U} / \mathrm{L}$ & $52.43 \pm 17.38$ & $49.38 \pm 13.61$ & $0.520 \|$ \\
\hline GPx & $\mathrm{nmol} / \mathrm{min} / \mathrm{mL}$ & $151.4 \pm 31.1$ & $140.1 \pm 34.9$ & $0.180 \|$ \\
\hline $\begin{array}{l}\text { Body Mass Index } \\
\text { Blood pressure }\end{array}$ & $\begin{array}{l}\mathrm{kg} / \mathrm{m}^{2} \\
\mathrm{mmHg}\end{array}$ & $22.2 \pm 3.1$ & $23.0 \pm 3.1$ & $0.357_{-}^{*}$ \\
\hline Systolic & & $116.3 \pm 10.6$ & $116.3 \pm 9.5$ & $0.943^{\|}$ \\
\hline Diastolic & & $72.0 \pm 11.6$ & $72.4 \pm 9.5$ & $0.971^{\Perp}$ \\
\hline Glucose & $\mathrm{mg} / \mathrm{dL}$ & $92.8 \pm 7.5$ & $92.3 \pm 6.9$ & $0.805_{-}^{*}$ \\
\hline
\end{tabular}

Note: Continuous variables are represented as means \pm standard deviations (SD) and compared by * Student T test or "Mann-Whitney U Test. Categorical variables are given as numbers (no) with percentages (\%) and compared by $\ddagger$ Pearson’s Chi-Squared Test, $₫$ Fisher's Exact Test, or $\S$ Linear-byLinear Association as appropriate. Abbreviations: ERW, electrolyzed-reduced water; MW, mineral water; d-ROMs, diacron-reactive oxygen metabolites; BAP, biological antioxidant potential; TBARS, thiobarbituric acid reactive substances; MDA, malondialdehyde; 8-OHdG, 8-hydroxy-2desoxyguanosine; oxLDL, oxidized low-density lipoprotein; GPx, glutathione peroxidase.

\subsection{Effect of Treatment on the Primary Outcome Variables: Biomarkers of Oxidative Stress}

Data were analyzed via repeated measures ANOVA using a within-subject factor of time, and a between-subject factor of group. The ERW group displayed a reduction in TBARS, 8-OHdG, and dROMs levels (mean \pm SD) and an increase in BAP and GPx levels (mean \pm SD) from baseline to 4 and 8 weeks follow-up (Table 2). 
The 1st International Electronic Conference on Antioxidants in Health and Disease, 1-15 December 2020

Table 2. Effect of treatment on the primary outcome variables: biomarkers of oxidative stress.

\begin{tabular}{|c|c|c|c|c|c|}
\hline \multirow[b]{2}{*}{ Outcome Variables } & \multirow{2}{*}{$\begin{array}{c}\begin{array}{c}\text { ERW } \\
(n=29)\end{array} \\
\text { Means } \pm \text { SD }\end{array}$} & \multirow{2}{*}{$\begin{array}{c}\text { MW } \\
(n=24)\end{array}$} & \multicolumn{3}{|c|}{$p$} \\
\hline & & & Time & Group & Time * Group \\
\hline \multicolumn{6}{|l|}{ d-ROMs (U.CARR) } \\
\hline Baseline & $301.3 \pm 68.6$ & $347.3 \pm 94.9$ & & & \\
\hline 4 weeks & $286.7 \pm 45.1$ & $306.3 \pm 54.8$ & 0.004 & 0.007 & 0.044 \\
\hline 8 weeks & $288.0 \pm 50.0$ & $349.6 \pm 62.7$ & & & \\
\hline \multicolumn{6}{|l|}{ BAP (umol/L) } \\
\hline Baseline & $2027.4 \pm 226.9$ & $2015.7 \pm 274.8$ & & & \\
\hline 4 weeks & $2585.9 \pm 258.8$ & $2504.8 \pm 187.8$ & 0.000 & 0.875 & 0.045 \\
\hline 8 weeks & $2603.9 \pm 255.9$ & $2670.4 \pm 180.2$ & & & \\
\hline \multicolumn{6}{|l|}{ TBARS (MDA) $(\mu \mathrm{M})$} \\
\hline Baseline & $9.88 \pm 4.67$ & $8.90 \pm 5.98$ & & & \\
\hline 4 weeks & $6.84 \pm 3.99$ & $8.95 \pm 6.14$ & 0.003 & 0.809 & 0.091 \\
\hline 8 weeks & $6.97 \pm 4.51$ & $6.63 \pm 4.47$ & & & \\
\hline \multicolumn{6}{|l|}{ 8-OHdG (ng/mL) } \\
\hline Baseline & $14.33 \pm 6.88$ & $10.90 \pm 6.42$ & & & \\
\hline 4 weeks & $13.87 \pm 8.31$ & $15.63 \pm 11.18$ & 0.033 & 0.594 & 0.138 \\
\hline 8 weeks & $11.87 \pm 7.90$ & $10.87 \pm 7.00$ & & & \\
\hline \multicolumn{6}{|l|}{ oxLDL (U/L) } \\
\hline Baseline & $52.43 \pm 17.38$ & $49.38 \pm 13.61$ & & & \\
\hline 4 weeks & $53.60 \pm 15.32$ & $52.00 \pm 12.94$ & 0.332 & 0.679 & 0.534 \\
\hline 8 weeks & $52.24 \pm 15.97$ & $52.1 \pm 12.99$ & & & \\
\hline \multicolumn{6}{|l|}{ GPx (nmol/min/mL) } \\
\hline Baseline & $151.4 \pm 31.1$ & $140.1 \pm 34.9$ & & & \\
\hline 4 weeks & $162.8 \pm 36.5$ & $161.7 \pm 37.9$ & 0.000 & 0.639 & 0.412 \\
\hline 8 weeks & $185.8 \pm 30.9$ & $189.6 \pm 23.6$ & & & \\
\hline
\end{tabular}

Note: * Interaction between Time and the Group. Abbreviations: d-ROMs, diacron-reactive oxygen metabolites; BAP, biological antioxidant potential; TBARS, thiobarbituric acid reactive substances; MDA, malondialdehyde; 8-OHdG, 8-hydroxy-2-desoxyguanosine; oxLDL, oxidized low-density lipoprotein; GPx, glutathione peroxidase.

The effect of time showed a significant difference in mean d-ROMs levels at different time points, $\mathrm{F}(1.68,85.65)=6.61, p=0.004$; and the main effect of the group displayed a significant difference in the mean $\mathrm{d}$-ROMs levels between the two groups, $\mathrm{F}(1,51)=8.04, p=0.007$. There was a significant interaction observed between the intervention and time on the d-ROMs levels, $\mathrm{F}(1.68,85.65)=3.44, p$ $=0.044$ (Table 2). Mean BAP levels significantly differed between time points, $\mathrm{F}(2,102)=258.47, p<$ 0.001. Regarding the effect of the group, no significant difference was observed in the mean BAP levels between the two groups, $\mathrm{F}(1,51)=0.03, p=0.875$. However, a significant interaction was observed between the group and time on BAP levels, $\mathrm{F}(2,102)=3.20, p=0.045$ (Table 2). Mean TBARS, 8 -OHdG, and GPx levels significantly differed between time points (TBARS: $\mathrm{F}(2,102)=6.23, p=0.003$; 8-OHdG: $\mathrm{F}(2,102)=3.52, p=0.033 ; \mathrm{GPx}: \mathrm{F}(2,102)=27.07, p<0.001)$.

\subsection{Effect of Treatment on the Secondary Outcome Variables: Biochemistry Parameters}

Mean NK cell activity significantly differed between different time points, $\mathrm{F}(2,102)=20.934, p$ $<0.001$. In contrast, the intervention did not exert a significant effect on mean NK cell activity between the two groups, $\mathrm{F}(1,51)=0.40, p=0.528$. The interaction between the group and time did not significantly influence mean NK cell activity, $\mathrm{F}(2,102)=1.26, p=0.289$ (Table 3). 
The 1st International Electronic Conference on Antioxidants in Health and Disease, 1-15 December 2020

Table 3. Effects of treatment on the secondary outcome variables: biochemistry parameters.

\begin{tabular}{|c|c|c|c|c|c|}
\hline \multirow[b]{2}{*}{ Outcome Variables } & \multirow{2}{*}{$\begin{array}{c}\text { ERW } \\
(n=29) \\
\text { Means } \pm \text { SD }\end{array}$} & \multirow{2}{*}{$\begin{array}{c}\text { MW } \\
(n=24)\end{array}$} & \multicolumn{3}{|c|}{$p$} \\
\hline & & & Time & Group & Time * Group \\
\hline \multicolumn{6}{|c|}{ NK Cell Activity (pg/mL) } \\
\hline Baseline & $949.0 \pm 810.7$ & $1263.4 \pm 905.2$ & & & \\
\hline 4 weeks & $1943.5 \pm 1109.2$ & $1829.0 \pm 1136.7$ & 0.000 & 0.528 & 0.289 \\
\hline 8 weeks & $1814.2 \pm 1091.8$ & $2042.0 \pm 964.9$ & & & \\
\hline \multicolumn{6}{|l|}{ Glucose (mg/dL) } \\
\hline Baseline & $92.8 \pm 7.5$ & $92.3 \pm 6.9$ & & & \\
\hline 4 weeks & $92.8 \pm 8.2$ & $92.1 \pm 6.0$ & 0.978 & 0.640 & 0.916 \\
\hline 8 weeks & $93.0 \pm 5.9$ & $91.8 \pm 6.2$ & & & \\
\hline \multicolumn{6}{|l|}{$\mathrm{HbA1c}(\mathrm{mg} / \mathrm{dL})$} \\
\hline Baseline & $5.2 \pm 0.3$ & $5.3 \pm 0.3$ & & & \\
\hline 4 weeks & $5.3 \pm 0.3$ & $5.4 \pm 0.2$ & 0.000 & 0.228 & 0.971 \\
\hline 8 weeks & $5.3 \pm 0.3$ & $5.4 \pm 0.3$ & & & \\
\hline \multicolumn{6}{|l|}{ Insulin (uU/mL) } \\
\hline Baseline & $8.65 \pm 3.78$ & $8.21 \pm 10.31$ & & & \\
\hline 4 weeks & $6.66 \pm 3.19$ & $7.18 \pm 4.76$ & 0.091 & 0.729 & 0.401 \\
\hline 8 weeks & $7.15 \pm 3.19$ & $8.50 \pm 6.78$ & & & \\
\hline \multicolumn{6}{|l|}{ HOMA-IR } \\
\hline Baseline & $2.21 \pm 0.93$ & $1.95 \pm 2.74$ & & & \\
\hline 4 weeks & $1.55 \pm 0.80$ & $1.65 \pm 1.15$ & 0.112 & 0.739 & 0.575 \\
\hline 8 weeks & $1.68 \pm 0.80$ & $1.98 \pm 1.61$ & & & \\
\hline \multicolumn{6}{|l|}{ A.G.E. (AU) } \\
\hline Baseline & $2.05 \pm 0.26$ & $2.04 \pm 0.27$ & & & \\
\hline 4 weeks & $1.83 \pm 0.32$ & $1.82 \pm 0.23$ & 0.000 & 0.767 & 0.246 \\
\hline 8 weeks & $1.82 \pm 0.34$ & $1.91 \pm 0.33$ & & & \\
\hline \multicolumn{6}{|l|}{ Cortisol (ng/mL) } \\
\hline Baseline & $80.81 \pm 35.53$ & $81.78 \pm 25.30$ & & & \\
\hline 4 weeks & $76.95 \pm 27.36$ & $79.06 \pm 41.63$ & 0.743 & 0.443 & 0.308 \\
\hline 8 weeks & $72.63 \pm 27.47$ & $85.70 \pm 26.27$ & & & \\
\hline \multicolumn{6}{|l|}{ Lactic Acid (mmol/L) } \\
\hline Baseline & $1.76 \pm 0.86$ & $1.52 \pm 0.55$ & & & \\
\hline 4 weeks & $1.65 \pm 0.65$ & $1.58 \pm 0.61$ & 0.454 & 0.699 & 0.093 \\
\hline 8 weeks & $1.44 \pm 0.45$ & $1.61 \pm 0.47$ & & & \\
\hline
\end{tabular}

Note: * Interaction between Time and the Group. Abbreviations: NK, natural killer; HbA1c, glycosylated hemoglobin; HOMA-IR, homeostatic model assessment for insulin resistance; A.G.E., advanced glycation end products; AU, arbitrary units.

\subsection{Effect of Treatment on the Secondary Outcome Variables: Body Composition, CAVI, HRV, and PhA}

Significant interactions between the group and time were observed in total fat mass, $\mathrm{F}(1.80$, $91.60)=3.43, p=0.041$, visceral fat mass, $\mathrm{F}(2,102)=3.76, p=0.027$, and subcutaneous fat mass, $\mathrm{F}(1.78$, $90.50)=3.29, p=0.047$ (Table 4). Regarding the effect of time, significant differences were observed in total fat mass, $\mathrm{F}(1.80,91.60)=10.12, p<0.001$, visceral fat mass $\mathrm{F}(2,102)=9.96, p<0.001$, and subcutaneous fat mass, $\mathrm{F}(1.78,90.50)=9.81, p<0.001$, at different time points (Table 4 ). 
The 1st International Electronic Conference on Antioxidants in Health and Disease, 1-15 December 2020

Table 4. Effects of treatment on the secondary outcome variables: fat mass, CAVI.

\begin{tabular}{cccccc}
\hline & $\begin{array}{c}\text { ERW } \\
(\boldsymbol{n}=\mathbf{2 9})\end{array}$ & $\begin{array}{c}\text { MW } \\
(\boldsymbol{n}=\mathbf{2 4})\end{array}$ & \multicolumn{2}{c}{$p$} & \\
\cline { 2 - 6 } Outcome Variables & Means \pm SD & Means \pm SD & Time & Group & Time * Group \\
\hline Fat Mass-Total (kg) & & & & & \\
Baseline & $16.21 \pm 4.88$ & $17.30 \pm 5.03$ & & & 0.041 \\
4 weeks & $16.18 \pm 5.00$ & $16.55 \pm 4.90$ & 0.000 & 0.678 & \\
8 weeks & $15.86 \pm 4.86$ & $16.10 \pm 5.31$ & & & \\
\hline Fat Mass-Visceral (kg) & & & & & \\
Baseline & $1.86 \pm 0.96$ & $2.00 \pm 0.95$ & & & \\
4 weeks & $1.87 \pm 1.00$ & $1.87 \pm 0.82$ & 0.000 & 0.846 & \\
8 weeks & $1.79 \pm 0.94$ & $1.80 \pm 0.93$ & & & \\
\hline Fat Mass-Subcutaneous (kg) & & & & & \\
Baseline & $14.36 \pm 3.96$ & $15.30 \pm 4.12$ & & & \\
4 weeks & $14.30 \pm 4.04$ & $14.69 \pm 4.11$ & 0.000 & 0.644 & \\
8 weeks & $14.07 \pm 3.96$ & $14.30 \pm 4.41$ & & & \\
\hline CAVI-Rt & & & & & \\
Baseline & $6.44 \pm 0.80$ & $6.36 \pm 1.06$ & & & \\
4 weeks & $6.32 \pm 0.80$ & $6.36 \pm 0.73$ & 0.627 & 0.738 & 0.615 \\
8 weeks & $6.18 \pm 0.69$ & $6.36 \pm 0.86$ & & & \\
\hline CAVI-Lt & & & & & \\
Baseline & $6.52 \pm 0.77$ & $6.48 \pm 1.11$ & & & \\
4 weeks & $6.38 \pm 0.83$ & $6.48 \pm 0.76$ & 0.444 & 0.577 & 0.677 \\
8 weeks & $6.23 \pm 0.69$ & $6.42 \pm 0.81$ & & & \\
\hline
\end{tabular}

Note: * Interaction between Time and the Group. Abbreviations: CAVI, cardio-ankle vascular index.

3.5. Effect of Treatment on the Secondary Outcome Variables: BEPSI-K, BFI, FSS

Table 5. Effects of treatment on the secondary outcome variables: BEPSI-K, BFI, FSS.

\begin{tabular}{|c|c|c|c|c|c|}
\hline \multirow[b]{2}{*}{ Outcome Variables } & \multirow{2}{*}{$\begin{array}{c}\text { ERW } \\
(n=29) \\
\text { Mean } \pm \text { SD }\end{array}$} & \multirow{2}{*}{$\begin{array}{c}\text { MW } \\
(n=24) \\
\text { Mean } \pm \text { SD }\end{array}$} & \multicolumn{3}{|c|}{$p$} \\
\hline & & & Time & Group & Time * Group \\
\hline \multicolumn{6}{|l|}{ BEPSI-K } \\
\hline Baseline & $1.82 \pm 0.65$ & $1.73 \pm 0.51$ & & & \\
\hline 4 weeks & $1.71 \pm 0.72$ & $1.73 \pm 0.51$ & 0.553 & 0.907 & 0.511 \\
\hline 8 weeks & $1.76 \pm 0.73$ & $1.78 \pm 0.56$ & & & \\
\hline \multicolumn{6}{|l|}{ BFI } \\
\hline \multicolumn{6}{|l|}{ BFI Global } \\
\hline Baseline & $4.14 \pm 2.09$ & $4.01 \pm 2.27$ & & & \\
\hline 4 weeks & $3.60 \pm 1.98$ & $3.56 \pm 2.09$ & 0.016 & 0.964 & 0.901 \\
\hline 8 weeks & $3.28 \pm 2.29$ & $3.38 \pm 2.28$ & & & \\
\hline \multicolumn{6}{|l|}{ BFI Severity } \\
\hline Baseline & $5.69 \pm 2.06$ & $5.36 \pm 2.45$ & & & \\
\hline 4 weeks & $5.49 \pm 1.77$ & $5.14 \pm 2.28$ & 0.049 & 0.566 & 0.956 \\
\hline 8 weeks & $4.90 \pm 2.32$ & $4.71 \pm 2.40$ & & & \\
\hline \multicolumn{6}{|l|}{ BFI Interference } \\
\hline Baseline & $3.36 \pm 2.39$ & $3.33 \pm 2.38$ & & & \\
\hline 4 weeks & $2.66 \pm 2.37$ & $2.76 \pm 2.30$ & 0.028 & 0.845 & 0.895 \\
\hline 8 weeks & $2.47 \pm 2.46$ & $2.72 \pm 2.41$ & & & \\
\hline
\end{tabular}


The 1st International Electronic Conference on Antioxidants in Health and Disease, 1-15 December 2020

\begin{tabular}{llllll} 
Baseline & $3.58 \pm 1.58$ & $3.65 \pm 1.68$ & & & \\
4 weeks & $3.15 \pm 1.53$ & $3.40 \pm 1.67$ & 0.172 & 0.928 & 0.489 \\
8 weeks & $3.39 \pm 1.81$ & $3.17 \pm 1.65$ & & & \\
\hline
\end{tabular}

Note: * Interaction between Time and the Group. Abbreviations: BEPSI-K, Brief Encounter

Psychosocial Instrument - Korean version; BFI, brief fatigue inventory; FSS, fatigue severity scale.

\section{Discussion}

This study was the first randomized, double-blind, placebo-controlled trial to assess the outcomes of specific lifestyle modification, namely drinking ERW at the workplace, in healthy adults. The majority of healthy adults spend most of their waking hours at work, so the workplace appears to be the ideal place to adopt a healthy lifestyle. Successful and sustainable lifestyle modifications must be accessible [81], affordable, and equitable to all individuals without discrimination or disparities $[43,82,83]$.

The BAP and d-ROMs tests have been widely used as biomarkers measuring the antioxidant activity and oxidative stress as a whole [52,55,84]. In this study, both biomarkers demonstrated a significant association between the group and timely intervention, indicating that eight weeks of consuming ERW may prove effective in both reducing oxidative stress and increasing antioxidant potential compared to drinking MW. The concentration of MDA and 8-OHdG in this study was measured using spot urine. However, there has been a controversy over whether to normalize biomarkers in urine with the concentration of urinary creatinine $(\mu \mathrm{Cr})$ since the rate of excretion of $\mu \mathrm{Cr}$ may change according to age, sex, exercise, diet, muscle mass, and stress [85]. Approximately $20 \%$ of the subjects were exercising at various intensities during the study period, so we chose not to perform normalization, considering the potential effect on the concentration of $\mu \mathrm{Cr}$.

It is known that ROS may change the surface charge of NK cells to negative, thereby disturbing the attachment of NK cells to target cancer cells, which are usually anionic [86]. pH-centered cancer care is attracting more and more attention in the field of oncology [87], and numerous studies have been attempted to modify the alkaline intracellular and acidic extracellular microenvironment of cancer cells $[87,88]$. The activity of NK cells showed a considerable increase from baseline $(949.0 \pm$ $810.68)$ to 4 weeks $(1943.5 \pm 1109.2)$ and 8 weeks $(1814.2 \pm 1091.8)$ in both the ERW and MW groups in this study. We may, therefore, cautiously postulate from the perspective of nutritional immunology that drinking ERW may be a potential candidate for cancer prevention [89-91].

Notably, most biomarkers of oxidative stress and health-related indices showed less improvement during the last 4 weeks compared to the first 4 weeks, and this effect may be attributed to the observed difference in the average intake of water between the two periods (1481 \pm 78 vs. 1311 $\pm 201, p<0.001$ ). Reduced intake of water due to busier schedules during the last 4 weeks might have affected the differences shown in outcome variables. There was one study related to the intake of blueberry, showing a blunted improvement of biomarkers of oxidative stress later in the intervention. One of the diverse interpretations suggested was that there might have been an acclimation leading to reduced oxidative damage over time [92].

In body composition analysis, total, visceral, and subcutaneous fat mass showed a more significant decrease over time in the ERW relative to the MW group. ERW might have directly induced lipolysis in adipocytes, downregulated the expression of transcription factors in the adipogenesis pathway, or reduced accumulation of lipids by affecting the expression of genes, such as fatty acid synthase (FAS), lipoprotein lipase (LPL), or hormone-sensitive lipase (HSL) during the differentiation of preadipocytes [93-95]. Additionally, ERW might have influenced the production of leptin or adiponectin [94,96], which would have accounted for the observed fat mass reduction.

A colonization pattern of microbiota has been known to be one of the contributing factors of obesity, while a higher ratio of Firmicutes over Bacteroidetes has been demonstrated as a pattern commonly seen in obese people [97-100]. One study showed that anaerobes and aerobes grow at environments of different oxidation-reduction potential (ORP), thus drinking ERW might favor the growth of anaerobes [101]. On the other hand, the ORP is an important component showing the 
The 1st International Electronic Conference on Antioxidants in Health and Disease, 1-15 December 2020

antioxidant potential of the reduced water. In a previous study comparing the ORP of reduced water with different $\mathrm{pH}$, an ERW sample with a $\mathrm{pH}$ close to 10 showed considerably higher negative ORP value in vitro compared to ERW with a $\mathrm{pH}$ of 9.5 [102]. In future studies, it is recommended to compare ERW with different $\mathrm{pH}$ and ORP values to find out the best outcome in terms of antioxidant potential. Platinum coated on titanium electrode plates is already commonly used and known to be effective; further research on new materials that may increase negative ORP, and the costeffectiveness [103] will allow more individuals to benefit from drinking ERW.

\section{Conclusions}

Drinking of ERW improved the major biomarkers of oxidative stress and body fat mass. Significant interactions were observed between the intervention and time on d-ROMs, BAP, and fat mass. Hence, drinking ERW on a daily basis may be effective in the reduction of oxidative stress and increase of antioxidant potential, as well as in the decrease of total body, visceral, and subcutaneous fat mass. However, additional research participants with a more extended study period as well as analysis of the ionic concentrations of ERW and MW are needed in future studies to definitively support the adoption of drinking ERW at the workplace as an effective, equitable, accessible, sustainable, and innovatively simple lifestyle modification for health promotion.

Author Contributions: Conceptualization, Y.A.C. and D.H.L.; methodology, Y.A.C., D.H.L., D.-Y.C., and Y.-J.L.; formal analysis, Y.A.C. and D.H.L.; investigation, Y.A.C. and D.H.L.; resources, Y.A.C.; writing-original draft preparation, Y.A.C.; writing-review and editing, Y.A.C., D.H.L., D.-Y.C., and Y.-J.L.; visualization, Y.A.C. and D.H.L.; supervision, D.H.L.; project administration, Y.A.C. and D.H.L.; funding acquisition, Y.A.C. All authors have read and agreed to the published version of the manuscript.

Funding: This research received no external funding.

Acknowledgments: This study was conducted with the support of the Health Fellowship Foundation. We would like to express our great appreciation to Bundang Jesaeng Hospital, ATGen, Co, Ltd. and GC Labs for providing us with test materials and technical support, and to Adam Lund, Young-Sang Kim and Kyoung Min Cho for their statistical assistance. The authors would like to thank Editage for the technical and language editing of the manuscript. Our deepest appreciation is toward colleagues at Bundang Jesaeng Hospital for their willingness to participate in the study amidst the busiest schedules.

Conflicts of Interest: The authors declare no conflict of interest.

\section{References}

1. Commoner, B.; Townsend, J.; Pake, G.E. Free radicals in biological materials. Nature 1954, 174, 689-691, doi:10.1038/174689a0.

2. Powers, S.K.; Jackson, M.J. Exercise-Induced Oxidative Stress: Cellular Mechanisms and Impact on Muscle Force Production. Physiol. Rev. 2008, 88, 1243-1276, doi:10.1152/physrev.00031.2007.

3. Bhattacharyya, A.; Chattopadhyay, R.; Mitra, S.; Crowe, S.E. Oxidative Stress: An Essential Factor in the Pathogenesis of Gastrointestinal Mucosal Diseases. Physiol. Rev. 2014, 94, 329-354, doi:10.1152/physrev.00040.2012.

4. Poljsak, B.; Šuput, D.; Milisav, I. Achieving the Balance between ROS and Antioxidants: When to Use the Synthetic Antioxidants. Oxidative Med. Cell. Longev. 2013, 2013, 956792, doi:10.1155/2013/956792.

5. Hohn, A.; Weber, D.; Jung, T.; Ott, C.; Hugo, M.; Kochlik, B.; Kehm, R.; Konig, J.; Grune, T.; Castro, J.P. Happily (n)ever after: Aging in the context of oxidative stress, proteostasis loss and cellular senescence. Redox Biol. 2017, 11, 482-501, doi:10.1016/j.redox.2016.12.001.

6. Chandrasekaran, A.; Idelchik, M.; Melendez, J.A. Redox control of senescence and age-related disease. Redox Biol. 2017, 11, 91-102, doi:10.1016/j.redox.2016.11.005.

7. Kochlik, B.; Grune, T.; Weber, D. New findings of oxidative stress biomarkers in nutritional research. Curr. Opin. Clin. Nutr. Metab. Care 2017, 20, 349-359, doi:10.1097/MCO.0000000000000388.

8. Liguori, I.; Russo, G.; Curcio, F.; Bulli, G.; Aran, L.; Della-Morte, D.; Gargiulo, G.; Testa, G.; Cacciatore, F.; Bonaduce, D.; et al. Oxidative stress, aging, and diseases. Clin. Interv. Aging 2018, 13, 757-772, doi:10.2147/cia.s158513. 
The 1st International Electronic Conference on Antioxidants in Health and Disease, 1-15 December 2020

9. Sies, H. Oxidative stress: A concept in redox biology and medicine. Redox Biol. 2015, 4, 180-183, doi:10.1016/j.redox.2015.01.002.

10. Venkataraman, K.; Khurana, S.; Tai, T.C. Oxidative stress in aging--matters of the heart and mind. Int. J. Mol. Sci. 2013, 14, 17897-17925, doi:10.3390/ijms140917897.

11. Therond, P.; Bonnefont-Rousselot, D.; Davit-Spraul, A.; Conti, M.; Legrand, A. Biomarkers of oxidative stress: An analytical approach. Curr. Opin. Clin. Nutr. Metab. Care 2000, 3, 373-384, doi:10.1097/00075197200009000-00009.

12. Shirahata, S.; Hamasaki, T.; Teruya, K. Advanced research on the health benefit of reduced water. Trends Food Sci. Technol. 2012, 23, 124-131.

13. Hanaoka, K.; Sun, D.; Lawrence, R.; Kamitani, Y.; Fernandes, G. The mechanism of the enhanced antioxidant effects against superoxide anion radicals of reduced water produced by electrolysis. Biophys. Chem. 2004, 107, 71-82, doi:10.1016/j.bpc.2003.08.007.

14. Shirahata, S.; Murakami, E.; Kusumoto, K.-I.; Yamashita, M.; Oda, M.; Temya, K.; Kabayama, S.; Otsubo, K.; Morisawa, S.; Hayashi, H. Telomere shortening in cancer cells by electrolyzed-reduced water. In Animal Cell Technology: Challenges for the 21st Century; Springer: Berlin/Heidelberg, Germany, 2002; pp. 355-359.

15. Shirahata, S.; Kabayama, S.; Nakano, M.; Miura, T.; Kusumoto, K.; Gotoh, M.; Hayashi, H.; Otsubo, K.; Morisawa, S.; Katakura, Y. Electrolyzed-reduced water scavenges active oxygen species and protects DNA from oxidative damage. Biochem. Biophys. Res. Commun. 1997, 234, 269-274, doi:10.1006/bbrc.1997.6622.

16. Franceschelli, S.; Gatta, D.M.; Pesce, M.; Ferrone, A.; Patruno, A.; de Lutiis, M.A.; Grilli, A.; Felaco, M.; Croce, F.; Speranza, L. New Approach in Translational Medicine: Effects of Electrolyzed Reduced Water (ERW) on NF-kappaB/iNOS Pathway in U937 Cell Line under Altered Redox State. Int. J. Mol. Sci. 2016, 17, doi:10.3390/ijms17091461.

17. Kashiwagi, T.; Yan, H.; Hamasaki, T.; Kinjo, T.; Nakamichi, N.; Teruya, K.; Kabayama, S.; Shirahata, S. Electrochemically reduced water protects neural cells from oxidative damage. Oxid. Med. Cell. Longev. 2014, 2014, 869121, doi:10.1155/2014/869121.

18. Ye, J.; Li, Y.; Hamasaki, T.; Nakamichi, N.; Komatsu, T.; Kashiwagi, T.; Teruya, K.; Nishikawa, R.; Kawahara, T.; Osada, K.; et al. Inhibitory effect of electrolyzed reduced water on tumor angiogenesis. Biol. Pharm. Bull. 2008, 31, 19-26, doi:10.1248/bpb.31.19.

19. Tsai, C.-F.; Hsu, Y.-W.; Chen, W.-K.; Ho, Y.-C.; Lu, F.-J. Enhanced Induction of Mitochondrial Damage and Apoptosis in Human Leukemia HL-60 Cells Due to Electrolyzed-Reduced Water and Glutathione. Biosci. Biotechnol. Biochem. 2009, 73, 280-287, doi:10.1271/bbb.80413.

20. Shirahata, S. Reduced water for prevention of diseases. In Animal Cell Technology: Basic E Applied Aspects; Springer: Berlin/Heidelberg, Germany, 2002; pp. 25-30.

21. Kinjo, T.; Ye, J.; Yan, H.; Hamasaki, T.; Nakanishi, H.; Toh, K.; Nakamichi, N.; Kabayama, S.; Teruya, K.; Shirahata, S. Suppressive effects of electrochemically reduced water on matrix metalloproteinase-2 activities and in vitro invasion of human fibrosarcoma HT1080 cells. Cytotechnology 2012, 64, 357-371, doi:10.1007/s10616-012-9469-7.

22. Hamasaki, T.; Nakamichi, N.; Teruya, K.; Shirahata, S. Removal efficiency of radioactive cesium and iodine ions by a flow-type apparatus designed for electrochemically reduced water production. PLoS ONE 2014, 9, e102218, doi:10.1371/journal.pone.0102218.

23. Kim, M.J.; Kim, H.K. Anti-diabetic effects of electrolyzed reduced water in streptozotocin-induced and genetic diabetic mice. Life Sci. 2006, 79, 2288-2292, doi:10.1016/j.1fs.2006.07.027.

24. Abe, M.; Sato, S.; Toh, K.; Hamasaki, T.; Nakamichi, N.; Teruya, K.; Katakura, Y.; Morisawa, S.; Shirahata, S. Suppressive effect of ERW on lipid peroxidation and plasma triglyceride level. In Animal Cell Technology: Basic \& Applied Aspects; Springer: Berlin/Heidelberg, Germany, 2010; pp. 315-321.

25. Spulber, S.; Edoff, K.; Hong, L.; Morisawa, S.; Shirahata, S.; Ceccatelli, S. Molecular hydrogen reduces LPSinduced neuroinflammation and promotes recovery from sickness behaviour in mice. PLoS ONE 2012, 7, e42078, doi:10.1371/journal.pone.0042078.

26. Cheng, T.C.; Hsu, Y.W.; Lu, F.J.; Chen, Y.Y.; Tsai, N.M.; Chen, W.K.; Tsai, C.F. Nephroprotective effect of electrolyzed reduced water against cisplatin-induced kidney toxicity and oxidative damage in mice. J. Chin. Med. Assoc. 2018, 81, 119-126, doi:10.1016/j.jcma.2017.08.014. 
The 1st International Electronic Conference on Antioxidants in Health and Disease, 1-15 December 2020

27. Yan, H.; Tian, H.; Kinjo, T.; Hamasaki, T.; Tomimatsu, K.; Nakamichi, N.; Teruya, K.; Kabayama, S.; Shirahata, S. Extension of the Lifespan ofCaenorhabditis elegansby the Use of Electrolyzed Reduced Water. Biosci. Biotechnol. Biochem. 2010, 74, 2011-2015, doi:10.1271/bbb.100250.

28. Magro, M.; Corain, L.; Ferro, S.; Baratella, D.; Bonaiuto, E.; Terzo, M.; Corraducci, V.; Salmaso, L.; Vianello, F. Alkaline Water and Longevity: A Murine Study. Evid Based Complement. Altern. Med. 2016, 2016, 3084126, doi:10.1155/2016/3084126.

29. Huang, K.-C.; Yang, C.-C.; Lee, K.-T.; Chien, C.-T. Reduced hemodialysis-induced oxidative stress in endstage renal disease patients by electrolyzed reduced water. Kidney Int. 2003, 64, 704-714, doi:10.1046/j.15231755.2003.00118.x.

30. Huang, K.C.; Yang, C.C.; Hsu, S.P.; Lee, K.T.; Liu, H.W.; Morisawa, S.; Otsubo, K.; Chien, C.T. Electrolyzedreduced water reduced hemodialysis-induced erythrocyte impairment in end-stage renal disease patients. Kidney Int. 2006, 70, 391-398, doi:10.1038/sj.ki.5001576.

31. Huang, K.C.; Hsu, S.P.; Yang, C.C.; Ou-Yang, P.; Lee, K.T.; Morisawa, S.; Otsubo, K.; Chien, C.T. Electrolysed-reduced water dialysate improves T-cell damage in end-stage renal disease patients with chronic haemodialysis. Nephrol. Dial. Transpl. 2010, 25, 2730-2737, doi:10.1093/ndt/gfq082.

32. Li, Y.; Hamasaki, T.; Teruya, K.; Nakamichi, N.; Gadek, Z.; Kashiwagi, T.; Yan, H.; Kinjo, T.; Komatsu, T.; Ishii, Y.; et al. Suppressive effects of natural reduced waters on alloxan-induced apoptosis and type 1 diabetes mellitus. Cytotechnology 2012, 64, 281-297, doi:10.1007/s10616-011-9414-1.

33. Masuda, K.; Tanaka, Y.; Kanehisa, M.; Ninomiya, T.; Inoue, A.; Higuma, H.; Kawashima, C.; Nakanishi, M.; Okamoto, K.; Akiyoshi, J. Natural reduced water suppressed anxiety and protected the heightened oxidative stress in rats. Neuropsychiatr. Dis. Treat. 2017, 13, 2357-2362, doi:10.2147/ndt.S138289.

34. Kitagawa, Y.; Liu, C.; Ding, X. The influence of natural mineral water on aquaporin water permeability and human natural killer cell activity. Biochem. Biophys. Res. Commun. 2011, 409, 40-45, doi:10.1016/j.bbrc.2011.04.102.

35. Wynn, E.; Krieg, M.A.; Aeschlimann, J.M.; Burckhardt, P. Alkaline mineral water lowers bone resorption even in calcium sufficiency: Alkaline mineral water and bone metabolism. Bone 2009, 44, 120-124, doi:10.1016/j.bone.2008.09.007.

36. Chycki, J.; Kurylas, A.; Maszczyk, A.; Golas, A.; Zajac, A. Alkaline water improves exercise-induced metabolic acidosis and enhances anaerobic exercise performance in combat sport athletes. PLoS ONE 2018, 13, e0205708, doi:10.1371/journal.pone.0205708.

37. Nakao, A.; Toyoda, Y.; Sharma, P.; Evans, M.; Guthrie, N. Effectiveness of hydrogen rich water on antioxidant status of subjects with potential metabolic syndrome-an open label pilot study. J. Clin. Biochem. Nutr. 2010, 46, 140-149, doi:10.3164/jcbn.09-100.

38. The Lancet Public Health. Public health and the workplace: A new era dawns. Lancet Public Health 2018, 3, e508, doi:10.1016/s2468-2667(18)30217-2.

39. Banerjee, P.; Gavaravarapu, S.M. Wellness programmes in the workplace in India. Lancet Public Health 2018, 3, e515, doi:10.1016/s2468-2667(18)30199-3.

40. Bergman, F.; Wahlström, V.; Stomby, A.; Otten, J.; Lanthén, E.; Renklint, R.; Waling, M.; Sörlin, A.; Boraxbekk, C.-J.; Wennberg, P.; et al. Treadmill workstations in office workers who are overweight or obese: A randomised controlled trial. Lancet Public Health 2018, 3, e523-e535, doi:10.1016/s2468-2667(18)30163-4.

41. Haufe, S.; Kerling, A.; Protte, G.; Bayerle, P.; Stenner, H.T.; Rolff, S.; Sundermeier, T.; Kuck, M.; Ensslen, R.; Nachbar, L.; et al. Telemonitoring-supported exercise training, metabolic syndrome severity, and work ability in company employees: A randomised controlled trial. Lancet Public Health 2019, 4, e343-e352, doi:10.1016/s2468-2667(19)30075-1.

42. Van Den Brand, F.A.; Nagelhout, G.E.; Winkens, B.; Chavannes, N.H.; Van Schayck, O.C.P. Effect of a workplace-based group training programme combined with financial incentives on smoking cessation: A cluster-randomised controlled trial. Lancet Public Health 2018, 3, e536-e544, doi:10.1016/s24682667(18)30185-3.

43. Fineberg, H.V. Shattuck Lecture. A successful and sustainable health system--how to get there from here. N. Engl. J. Med. 2012, 366, 1020-1027, doi:10.1056/NEJMsa1114777.

44. Faul, F.; Erdfelder, E.; Lang, A.-G.; Buchner, A. G*Power 3: A flexible statistical power analysis program for the social, behavioral, and biomedical sciences. Behav. Res. Methods 2007, 39, 175-191, doi:10.3758/bf03193146. 
The 1st International Electronic Conference on Antioxidants in Health and Disease, 1-15 December 2020

45. Friedman, L.M.; Furberg, C.; DeMets, D.L.; Reboussin, D.M.; Granger, C.B. Fundamentals of Clinical Trials; Springer: Berlin/Heidelberg, Germany, 2010; Volume 4.

46. Sakpal, T.V. Sample size estimation in clinical trial. Perspect. Clin. Res. 2010, 1, 67-69.

47. R Core Team. A Language and Environment for Statistical Computing; R Foundation for Statistical Computing: Vienna, Austria, 2017; Volume 30. Available online: http. www. R-Proj. . Org. (accessed on 2018).

48. Kotani, K.; Sakane, N. C-reactive protein and reactive oxygen metabolites in subjects with metabolic syndrome. J. Int. Med. Res. 2012, 40, 1074-1081, doi:10.1177/147323001204000326.

49. Sugiura, T.; Dohi, Y.; Takase, H.; Yamashita, S.; Tanaka, S.; Kimura, G. Increased reactive oxygen metabolites is associated with cardiovascular risk factors and vascular endothelial damage in middle-aged Japanese subjects. Vasc. Health Risk Manag. 2011, 7, 475-482, doi:10.2147/vhrm.S23097.

50. Yagi, H.; Sumino, H.; Yoshida, K.; Aoki, T.; Tsunekawa, K.; Araki, O.; Kimura, T.; Nara, M.; Nakajima, K.; Murakami, M. Biological antioxidant potential negatively correlates with carotid artery intima-media thickness. Int. Heart J. 2016, 57, 220-225.

51. Cesarone, M.R.; Belcaro, G.; Carratelli, M.; Cornelli, U.; De Sanctis, M.T.; Incandela, L.; Barsotti, A.; Terranova, R.; Nicolaides, A. A simple test to monitor oxidative stress. Int. Angiol. 1999, 18, 127-130.

52. Fattoretti, P.; Malavolta, M.; Fabbietti, P.; Papa, R.; Giacconi, R.; Costarelli, L.; Galeazzi, R.; Paoloni, C.; Postacchini, D.; Lattanzio, F.; et al. Oxidative Stress in Elderly with Different Cognitive Status: My Mind Project. J. Alzheimers Dis. 2018, 63, 1405-1414, doi:10.3233/jad-171117.

53. Celi, P.; Sullivan, M.; Evans, D. The stability of the reactive oxygen metabolites (d-ROMs) and biological antioxidant potential (BAP) tests on stored horse blood. Vet. J. 2010, 183, 217-218, doi:10.1016/j.tvjl.2008.09.018.

54. Kitada, M.; Ogura, Y.; Maruki-Uchida, H.; Sai, M.; Suzuki, T.; Kanasaki, K.; Hara, Y.; Seto, H.; Kuroshima, Y.; Monno, I.; et al. The Effect of Piceatannol from Passion Fruit (Passiflora edulis) Seeds on Metabolic Health in Humans. Nutrients 2017, 9, 1142, doi:10.3390/nu9101142.

55. Benzie, I.F.; Strain, J.J. The ferric reducing ability of plasma (FRAP) as a measure of "antioxidant power": The FRAP assay. Anal. Biochem. 1996, 239, 70-76, doi:10.1006/abio.1996.0292.

56. Dokumacioglu, E.; Demiray, O.; Dokumacioglu, A.; Sahin, A.; Sen, T.M.; Cankaya, S. Measuring urinary 8hydroxy-2'-deoxyguanosine and malondialdehyde levels in women with overactive bladder. Investig. Clin. Urol. 2018, 59, 252-256, doi:10.4111/icu.2018.59.4.252.

57. Basavaraj, K.H.; Vasu Devaraju, P.; Rao, K.S. Studies on serum 8-hydroxy guanosine (8-OHdG) as reliable biomarker for psoriasis. J. Eur. Acad. Dermatol. Venereol. 2013, 27, 655-657, doi:10.1111/j.14683083.2011.04441.x.

58. Sarmiento, A.; Diaz-Castro, J.; Pulido-Moran, M.; Moreno-Fernandez, J.; Kajarabille, N.; Chirosa, I.; Guisado, I.M.; Javier Chirosa, L.; Guisado, R.; Ochoa, J.J. Short-term ubiquinol supplementation reduces oxidative stress associated with strenuous exercise in healthy adults: A randomized trial. BioFactors 2016, 42, 612-622, doi:10.1002/biof.1297.

59. Wheeler, C.R.; Salzman, J.A.; Elsayed, N.M.; Omaye, S.T.; Korte, D.W., Jr. Automated assays for superoxide dismutase, catalase, glutathione peroxidase, and glutathione reductase activity. Anal. Biochem. 1990, 184, 193-199, doi:10.1016/0003-2697(90)90668-y.

60. Zabłocka-Słowińska, K.; Płaczkowska, S.; Prescha, A.; Pawełczyk, K.; Porębska, I.; Kosacka, M.; PawlikSobecka, L.; Grajeta, H. Serum and whole blood $\mathrm{Zn}, \mathrm{Cu}$ and $\mathrm{Mn}$ profiles and their relation to redox status in lung cancer patients. J. Trace Elem. Med. Biol. 2018, 45, 78-84, doi:10.1016/j.jtemb.2017.09.024.

61. Zhang, F.; Ren, Y.; Fu, W.; Wang, Y.; Qian, J.; Tao, C.; You, C.; Yang, M. Association between neutrophil to lymphocyte ratio and blood glucose level at admission in patients with spontaneous intracerebral hemorrhage. Sci. Rep. 2019, 9, 1-9.

62. Hitsumoto, T. Association of hemorheology with high-sensitivity cardiac troponin T levels in patients with type 2 diabetes mellitus assessed by microchannel array flow analyzer. Cardiol. Res. 2017, 8, 304.

63. Jobin, G.; Rodriguez-Suarez, R.; Betito, K. Association Between Natural Killer Cell Activity and Colorectal Cancer in High-Risk Subjects Undergoing Colonoscopy. Gastroenterology 2017, 153, 980-987, doi:10.1053/j.gastro.2017.06.009.

64. Van Waateringe, R.P.; Slagter, S.N.; van Beek, A.P.; van der Klauw, M.M.; van Vliet-Ostaptchouk, J.V.; Graaff, R.; Paterson, A.D.; Lutgers, H.L.; Wolffenbuttel, B.H.R. Skin autofluorescence, a non-invasive 
The 1st International Electronic Conference on Antioxidants in Health and Disease, 1-15 December 2020

biomarker for advanced glycation end products, is associated with the metabolic syndrome and its individual components. Diabetol. Metab. Syndr. 2017, 9, 42, doi:10.1186/s13098-017-0241-1.

65. Meerwaldt, R.; Graaff, R.; Oomen, P.H.N.; Links, T.P.; Jager, J.J.; Alderson, N.L.; Thorpe, S.R.; Baynes, J.W.; Gans, R.O.B.; Smit, A.J. Simple non-invasive assessment of advanced glycation endproduct accumulation. Diabetologia 2004, 47, 1324-1330, doi:10.1007/s00125-004-1451-2.

66. Van Waateringe, R.P.; Fokkens, B.T.; Slagter, S.N.; van der Klauw, M.M.; van Vliet-Ostaptchouk, J.V.; Graaff, R.; Paterson, A.D.; Smit, A.J.; Lutgers, H.L.; Wolffenbuttel, B.H.R. Skin autofluorescence predicts incident type 2 diabetes, cardiovascular disease and mortality in the general population. Diabetologia 2019, 62, 269-280, doi:10.1007/s00125-018-4769-X.

67. Morioka, N.; Funada, J.; Takata, Y.; Hashida, H.; Iwata, T.; Higaki, J.; Okayama, H. Influence of meal intake on pulse wave indices in type 2 diabetes. Hypertens. Res. 2010, 33, 743-747, doi:10.1038/hr.2010.66.

68. Shirai, K.; Utino, J.; Otsuka, K.; Takata, M. A Novel Blood Pressure-independent Arterial Wall Stiffness Parameter; Cardio-Ankle Vascular Index (CAVI). J. Atheroscler. Thromb. 2006, 13, 101-107, doi:10.5551/jat.13.101.

69. Wakabayashi, I.; Masuda, H. Association of acute-phase reactants with arterial stiffness in patients with type 2 diabetes mellitus. Clin. Chim. Acta 2006, 365, 230-235, doi:10.1016/j.cca.2005.08.023.

70. Saiki, A.; Sato, Y.; Watanabe, R.; Watanabe, Y.; Imamura, H.; Yamaguchi, T.; Ban, N.; Kawana, H.; Nagumo, A.; Nagayama, D.; et al. The Role of a Novel Arterial Stiffness Parameter, Cardio-Ankle Vascular Index (CAVI), as a Surrogate Marker for Cardiovascular Diseases. J. Atheroscler. Thromb. 2016, 23, 155-168, doi:10.5551/jat.32797.

71. Shirai, K.; Hiruta, N.; Song, M.; Kurosu, T.; Suzuki, J.; Tomaru, T.; Miyashita, Y.; Saiki, A.; Takahashi, M.; Suzuki, K.; et al. Cardio-Ankle Vascular Index (CAVI) as a Novel Indicator of Arterial Stiffness: Theory, Evidence and Perspectives. J. Atheroscler. Thromb. 2011, 18, 924-938, doi:10.5551/jat.7716.

72. Jong, G.-J.; Horng, G.-J. The PPG Physiological Signal for Heart Rate Variability Analysis. Wirel. Pers. Commun. 2017, 97, 5229-5276.

73. Park, S.K.; Tucker, K.L.; O’Neill, M.S.; Sparrow, D.; Vokonas, P.S.; Hu, H.; Schwartz, J. Fruit, vegetable, and fish consumption and heart rate variability: The Veterans Administration Normative Aging Study. Am. J. Clin. Nutr. 2009, 89, 778-786, doi:10.3945/ajcn.2008.26849.

74. Tomeleri, C.M.; Cavaglieri, C.R.; de Souza, M.F.; Cavalcante, E.F.; Antunes, M.; Nabbuco, H.C.G.; Venturini, D.; Barbosa, D.S.; Silva, A.M.; Cyrino, E.S. Phase angle is related with inflammatory and oxidative stress biomarkers in older women. Exp. Gerontol. 2018, 102, 12-18, doi:10.1016/j.exger.2017.11.019.

75. Tan, R.S.; Liang, D.H.; Liu, Y.; Zhong, X.S.; Zhang, D.S.; Ma, J. Bioelectrical Impedance Analysis-Derived Phase Angle Predicts Protein-Energy Wasting in Maintenance Hemodialysis Patients. J. Ren. Nutr. 2019, 29, 295-301, doi:10.1053/j.jrn.2018.09.001.

76. Frank, S.H.; Zyzanski, S.J. Stress in the clinical setting: The Brief Encounter Psychosocial Instrument. J. Fam Pr. 1988, 26, 533-539.

77. Yim, J.; Bae, J.; Choi, S.; Kim, S.; Hwang, H.; Huh, B. The validity of modified Korean-translated BEPSI (Brief Encounter Psychosocial Instrument) as instrument of stress measurement in outpatient clinic. $J$. Korean Acad. Fam. Med. 1996, 17, 42-53.

78. Mendoza, T.R.; Wang, X.S.; Cleeland, C.S.; Morrissey, M.; Johnson, B.A.; Wendt, J.K.; Huber, S.L. The rapid assessment of fatigue severity in cancer patients: Use of the Brief Fatigue Inventory. Cancer 1999, 85, 11861196, doi:10.1002/(sici)1097-0142(19990301)85:5<1186::aid-cncr24>3.0.co;2-n.

79. Krupp, L.B.; LaRocca, N.G.; Muir-Nash, J.; Steinberg, A.D. The fatigue severity scale. Application to patients with multiple sclerosis and systemic lupus erythematosus. Arch. Neurol. 1989, 46, 1121-1123, doi:10.1001/archneur.1989.00520460115022.

80. Ware, J.E., Jr.; Sherbourne, C.D. The MOS 36-item short-form health survey (SF-36). I. Conceptual framework and item selection. Med. Care 1992, 30, 473-483.

81. Hone, T.; Macinko, J.; Millett, C. Revisiting Alma-Ata: What is the role of primary health care in achieving the Sustainable Development Goals? Lancet 2018, 392, 1461-1472.

82. Kluge, H.; Kelley, E.; Barkley, S.; Theodorakis, P.N.; Yamamoto, N.; Tsoy, A.; Aiypkhanova, A.; Ganesh, V.; Hipgrave, D.B.; Peterson, S.S. How primary health care can make universal health coverage a reality, ensure healthy lives, and promote wellbeing for all. Lancet 2018, 392, 1372-1374. 
The 1st International Electronic Conference on Antioxidants in Health and Disease, 1-15 December 2020

83. Organization, W.H. Astana Declaration of primary health care: From Alm-Ata towards universal health coverage and sustainable development goals. 2018. 2019.

84. Marrocco, I.; Altieri, F.; Peluso, I. Measurement and Clinical Significance of Biomarkers of Oxidative Stress in Humans. Oxid. Med. Cell. Longev. 2017, 2017, 6501046, doi:10.1155/2017/6501046.

85. Tang, K.W.; Toh, Q.C.; Teo, B.W. Normalisation of urinary biomarkers to creatinine for clinical practice and research-When and why. Singap. Med. J. 2015, 56, 7-10, doi:10.11622/smedj.2015003.

86. Nakamura, K.; Matsunaga, K. Susceptibility of natural killer (NK) cells to reactive oxygen species (ROS) and their restoration by the mimics of superoxide dismutase (SOD). Cancer Biother. Radiopharm. 1998, 13, 275-290, doi:10.1089/cbr.1998.13.275.

87. Harguindey, S.; Reshkin, S.J. "The new pH-centric anticancer paradigm in Oncology and Medicine"; SCB, 2017. Semin. Cancer Biol. 2017, 43, 1-4, doi:10.1016/j.semcancer.2017.02.008.

88. Dumas, J.F.; Brisson, L.; Chevalier, S.; Maheo, K.; Fromont, G.; Moussata, D.; Besson, P.; Roger, S. Metabolic reprogramming in cancer cells, consequences on $\mathrm{pH}$ and tumour progression: Integrated therapeutic perspectives with dietary lipids as adjuvant to anticancer treatment. Semin. Cancer Biol. 2017, 43, 90-110, doi:10.1016/j.semcancer.2017.03.004.

89. Kim, Y.S.; Sayers, T.J.; Colburn, N.H.; Milner, J.A.; Young, H.A. Impact of dietary components on NK and Treg cell function for cancer prevention. Mol. Carcinog. 2015, 54, 669-678.

90. Leischner, C.; Burkard, M.; Pfeiffer, M.M.; Lauer, U.M.; Busch, C.; Venturelli, S.J.N.j. Nutritional immunology: Function of natural killer cells and their modulation by resveratrol for cancer prevention and treatment. Nutr. J. 2015, 15, 47.

91. Grudzien, M.; Rapak, A. Effect of natural compounds on NK cell activation. J. Immunol. Res. 2018, 2018, 4868417.

92. Johnson, S.A.; Feresin, R.G.; Navaei, N.; Figueroa, A.; Elam, M.L.; Akhavan, N.S.; Hooshmand, S.; Pourafshar, S.; Payton, M.E.; Arjmandi, B.H. Effects of daily blueberry consumption on circulating biomarkers of oxidative stress, inflammation, and antioxidant defense in postmenopausal women with pre-and stage 1-hypertension: A randomized controlled trial. Food Funct. 2017, 8, 372-380.

93. Kowalska, K.; Olejnik, A.; Rychlik, J.; Grajek, W. Cranberries (Oxycoccus quadripetalus) inhibit lipid metabolism and modulate leptin and adiponectin secretion in 3T3-L1 adipocytes. Food Chem. 2015, 185, 383-388.

94. Kowalska, K.; Olejnik, A.; Szwajgier, D.; Olkowicz, M. Inhibitory activity of chokeberry, bilberry, raspberry and cranberry polyphenol-rich extract towards adipogenesis and oxidative stress in differentiated 3T3-L1 adipose cells. PLoS ONE 2017, 12, e0188583.

95. Martino, H.S.D.; dos Santos Dias, M.M.; Noratto, G.; Talcott, S.; Mertens-Talcott, S.U. Anti-lipidaemic and anti-inflammatory effect of açai (Euterpe oleracea Martius) polyphenols on 3T3-L1 adipocytes. J. Funct. Foods 2016, 23, 432-443.

96. Stern, J.H.; Rutkowski, J.M.; Scherer, P.E. Adiponectin, leptin, and fatty acids in the maintenance of metabolic homeostasis through adipose tissue crosstalk. Cell Metab. 2016, 23, 770-784.

97. Muscogiuri, G.; Cantone, E.; Cassarano, S.; Tuccinardi, D.; Barrea, L.; Savastano, S.; Colao, A. Gut microbiota: A new path to treat obesity. Int. J. Obes. Suppl. 2019, 9, 10-19.

98. Parekh, P.J.; Balart, L.A.; Johnson, D.A. The influence of the gut microbiome on obesity, metabolic syndrome and gastrointestinal disease. Clin. Transl. Gastroenterol. 2015, 6, e91.

99. Tseng, C.-H.; Wu, C.-Y. The gut microbiome in obesity. J. Formos. Med. Assoc. 2019, 118, S3-S9.

100. Turnbaugh, P.J.; Ley, R.E.; Mahowald, M.A.; Magrini, V.; Mardis, E.R.; Gordon, J.I. An obesity-associated gut microbiome with increased capacity for energy harvest. Nature 2006, 444, 1027.

101. Vorobjeva, N. Selective stimulation of the growth of anaerobic microflora in the human intestinal tract by electrolyzed reducing water. Med. Hypotheses 2005, 64, 543-546.

102. Hamasaki, T.; Harada, G.; Nakamichi, N.; Kabayama, S.; Teruya, K.; Fugetsu, B.; Gong, W.; Sakata, I.; Shirahata, S. Electrochemically reduced water exerts superior reactive oxygen species scavenging activity in HT1080 cells than the equivalent level of hydrogen-dissolved water. PLoS ONE 2017, 12, e0171192, doi:10.1371/journal.pone.0171192.

103. Ganesan, P.; Sivanantham, A.; Shanmugam, S. Nanostructured Nickel-Cobalt-Titanium Alloy Grown on Titanium Substrate as Efficient Electrocatalyst for Alkaline Water Electrolysis. ACS Appl. Mater. Interfaces 2017, 9, 12416-12426, doi:10.1021/acsami.7b00353. 
The 1st International Electronic Conference on Antioxidants in Health and Disease, 1-15 December 2020

(C) 2020 by the authors; licensee MDPI, Basel, Switzerland. This article is an open access article distributed under the terms and conditions of the Creative Commons by Attribution (CC-BY) license (http://creativecommons.org/licenses/by/4.0/). 